\title{
Pulmonary Vascular Response to Acetylcholine in Isolated Rat Lungs Treated with Intratracheal Bleomycin
}

\author{
Shinobu Sato, Shuichi Kato, Hihumi Takahashi, \\ Keiji Takahashi and Shoji Yasui \\ The First Department of Internal Medicine, Yamagata \\ University School of Medicine, Yamagata 990-23
}

\begin{abstract}
Sato, S., Kato, S., Takahashi, H., Takahashi, K. and Yasui, S. Pulmonary Vascular Response to Acetylcholine in Isolated Rat Lungs Treated with Intratracheal Bleomycin. Tohoku J. Exp. Med., 1990, 161 (2), 73-83—We tested the hypothesis that during alveolar hypoxia the vasodilator response to acetylcholine $(\mathrm{ACh})$ is impaired in lungs injured by intratracheal bleomycin. Isolated rat lungs were ventilated with normoxic $\left(21 \% \mathrm{O}_{2}\right)$ or hypoxic $\left(2 \% \mathrm{O}_{2}\right)$ gas and perfused with homologous blood. The effect of $\mathrm{ACh}$ on pulmonary vascular resistance was estimated during ongoing hypoxic pulmonary vasoconstriction (HPVC) after the temporal pattern of HPVC was established. The magnitude of the decrease in pulmonary vascular resistance was significantly smaller in the bleomycin-treated group (group $\mathrm{B}, n=7$ ) than in the saline-treated group (group $\mathrm{S}, n=7)(p<0.05$ ). The magnitude of HPVC itself did not differ between groups. The pulmonary vascular reactivities to angiotensin $\mathrm{II}$ and $\mathrm{KCl}$ were similar in the two groups (group $\mathrm{S}, n=4$, group $\mathrm{B}, n=5$ ). At any given transpulmonary pressure the lung volumes of group $\mathrm{B}(n=5)$ were significantly smaller than those of group $\mathrm{S}(n=$ 4) $(p<0.01)$. We conclude that vascular dilation in response to $\mathrm{ACh}$ during ongoing HPVC was impaired in bleomycin-injured rat lungs. - hypoxic pulmonary vasoconstriction; interstitial pulmonary fibrosis ; endothelium-derived relaxing factor
\end{abstract}

Interstitial pulmonary fibrosis produced by intratracheally administered bleomycin has been widely used as a disease model resembling in many aspects human idiopathic pulmonary fibrosis (Snider et al. 1978a, b). In this model a lung endothelial dysfunction, as well as a structural damage, is produced (Catravas et al. 1983; Fasske and Morgenroth 1983). Then the release of an endothelium-derived relaxing factor(s) (EDRF) (De Mey and Vanhoutte 1982) may be altered. An important role for EDRF in pulmonary vascular response to acute alveolar hypoxia has been recently suggested (De Mey and Vanhoutte 1982 ; Holden and McCall 1984 ; Brashers et al. 1988). The present study was designed to test the hypothesis that during alveolar hypoxia the dilator response to acetylcholine (ACh) (Furchgott and Zawadzki 1980) is altered in the model of

Received February 9, 1990; revision accepted for publication April 28, 1990. 
interstitial pulmonary fibrosis produced by bleomycin. Isolated rat lungs were perfused with homologous rat blood. In experiment 1, the magnitude of hypoxic pulmonary vasoconstriction (HPVC) as a function of time after exposure to hypoxic ventilatory gas was obtained to determine the period for $\mathrm{ACh}$ infusion in our experimental system. In experiment 2 , the vascular response to $\mathrm{ACh}$ were measured at the period determined in experiment 1. ACh was infused during ongoing HPVC. ACh was used to estimate the ability to release vasodilatave substances which is endothelium dependent (Boeynaems and Galand 1983; Feddersen et al. 1986). In experiment 3, the vascular response to angiotensin II and potassium chloride $(\mathrm{KCl})$ were estimated. Angiotensin II was used as a reference vasoconstrictor (McMurtry et al. 1976). In experiment 4, excised lung pressure-volume curves were obtained to functionally demonstrate induction of pulmonary fibrosis.

\section{Materials and Methods}

Male Wistar rats were used in all experiments. The animals used for the lung preparations were anesthetized with an intraperitoneal injection of $7 \mathrm{mg} / 100 \mathrm{~g}$ body weight of pentobarbital sodium (Somnopentyl, Pitman-Moore, Washington Crossing, NJ, USA), and animals used for blood donor (300-370 g) were anesthetized with ether.

Isolated lung preparation. Lungs were isolated and perfused according to the technique described by Hauge (1968) and modified by McMurtry et al. (1976). A tracheostomy was followed by positive-pressure ventilation with air using a rodent respirator (Model 683, Harvard Equipment, Boston, MA, USA) at 80 breaths/min. The peak inspiratory pressure was adjusted to $10 \mathrm{cmH}_{2} \mathrm{O}$ with end-expiratory pressure at $2 \mathrm{cmH}_{2} \mathrm{O}$ to prevent total collapse of the lung when the chest was opened. The ventilatory gas, air, was warmed by passage through water at $38^{\circ} \mathrm{C}$. The trachea and the lungs were freed from adjacent tissue, and a solution of heparin (40 IU/100 g weight) was slowly injected into the left ventricle before ligation of any vessels. Stainless steel cannulae were in serted into the main pulmonary artery through the right ventricle and into the left atrium through the left ventricle. The lungs, heart, and the pulmonary vessels were removed en block to a humidified and constant-temperature chamber $\left(37-38^{\circ} \mathrm{C}\right)$ and suspended by the trachea and the vessel cannulae. After several slow inflations the ventilatory gas was changed from room air to a mixture of $21 \% \mathrm{O}_{2}, 5 \% \mathrm{CO}_{2}$, and $74 \% \mathrm{~N}_{2}$ (normoxic gas). The tidal volume was readjusted so that the peak inspiratory pressure ( $\mathrm{Paw}$ ) was $8-9 \mathrm{cmH}_{2} \mathrm{O}$ and endexpiratory pressure was $2.5 \mathrm{cmH}_{2} \mathrm{O}$. This pressure was kept constant throughout each experiment.

We began the perfusion within 12 min of interruption of the animal's own circulation using a roller pump (Masterflex; Cole-Parmer Instrument, Chicago, IL, USA). The outflow pressure was maintained at $2 \mathrm{cmH}_{2} \mathrm{O}$ in all experiments. The inflow (Ppa) and outflow (Ppv) pressures were measured with pressure transducers (TP-101T; Nihon Kohden, Tokyo) connected to a pen recorder (Recti Horiz 8S ; San-Ei Instrument, Tokyo). The pressure transducers were zeroed at the lung hilum level. Once the flow for given lungs was established, it was held constant throughout the experiment. The stainless steel cannulae were siliconized. The silicone tubings and siliconized blood reservoir were renewed each time to avoid contamination by unknown vasoactive substances.

The perfusate consisted of $15 \mathrm{ml}$ of heparinized blood $(10 \mathrm{IU} / \mathrm{ml})$ obtained by cardiac puncture from blood donor rats and $5 \mathrm{ml}$ of Krebs-Ringer solution. The perfusate blood was kept in a closed plastic syringe at $5 \mathrm{C}$ for approximately $25 \mathrm{~min}$, then in a semi-closed perfusion circuit at $37^{\circ} \mathrm{C}$ until 15 to $20 \mathrm{~min}$ prior to the beginning of circulation. Sodium- 
bicarbonate was added to the perfusate to maintain $\mathrm{pH}$ between 7.35 and 7.48. As required, $0.2 \mathrm{ml}$ of effluent blood withdrawn through an orifice in the pulmonary venous line or influent blood taken at the connecting site of the pulmonary arterial line with the blood reservoir, was analyzed for oxygen tension $\left(\mathrm{PO}_{2}\right)$, carbon dioxide tension $\left(\mathrm{PCO}_{2}\right)$, and $\mathrm{pH}$ at $37^{\circ} \mathrm{C}$ with a Radiometer $\mathrm{ABL}-2$ system.

Experiment 1: Magnitude of HPVC versus time after alveolar hypoxia. Twelve animals were divided to two groups (a bleomycin-treated group, group B, $n=6,240-350 \mathrm{~g}$ at the time of sacrifice, and a saline-treated group, group $\mathrm{S}, n=6,265-360 \mathrm{~g}$ ). To the animals of group $\mathrm{B}$ a single endotracheal instillation of bleomycin sulfate was administered ( $0.4 \mathrm{mg}$ in $0.1 \mathrm{ml}$ saline $/ 100 \mathrm{~g}$ body weight) (Snider et al. 1978a, b). To group S, $0.1 \mathrm{ml}$ of saline/100 g body weight was instilled intratracheally. Four weeks after instillation, hypoxic pressor response was tested. The lungs were equilibrated for 20 min with normoxic gas. The equilibration time was followed by alternative $10 \mathrm{~min}$ periods of hypoxic $\left(2 \% \mathrm{O}_{2}\right.$, $5 \% \mathrm{CO}_{2}$ and $93 \% \mathrm{~N}_{2}$ ) and normoxic ventilation. This cycle was repeated three times and the third HPVC was analyzed. Since flow rate, resistance to effluent flow, and ventilatory rate and pressure were held constant, change in Ppa represented change in total pulmonary vascular resistance. The magnitude of the pressor response was estimated as the absolute increase in perfusion pressure from the base line pressure, i.e., Ppa, immediately before the start of hypoxic challenge.

Experiment 2: Dilator response to ACh during ongoing HPVC. Fourteen animals (group B, $n=7,230-280 \mathrm{~g}$ at the time of sacrifice and group S, $n=7,260-320 \mathrm{~g}$ ) were used for this part of the experiment. Following an equilibration period of $20 \mathrm{~min}$, ventilatory gas was switched to the hypoxic gas. The hypoxic time was set to 4 min since the HPVC became plateau approximately 4 min after hypoxic challenge in our experimental system as shown in the result of experiment 1 . After $4 \mathrm{~min}$ of ventilation with the hypoxic gas the ventilatory gas was switched back to the normoxic gas. Ten min were allowed for reequilibration. This cycle was repeated until the magnitude of the HPVC equaled or became less than the magnitude of the preceding response, i.e., until the temporal pattern of the pressor response was established. During the first hypoxic challenge after establishment of the temporal pattern, $\mathrm{ACh}$ was injected. Dilator response to $\mathrm{ACh}$ was elicited by close arterial bolus injection of $2.5 \mu \mathrm{g} \mathrm{ACh}$ in $0.2 \mathrm{ml}$ saline for $20 \mathrm{sec}, 4 \mathrm{~min}$ after the start of the hypoxic challenge.

Experiment 3: Pressor response to angiotensin II and $\mathrm{KCl}$. Nine animals (group B, $n=5,250-300 \mathrm{~g}$ at the time of sacrifice and group $\mathrm{S}, n=4,280-300 \mathrm{~g}$ ) were prepared. The perfusate flow rate was set to $10 \mathrm{ml} / \mathrm{min}$. After equilibration for $20 \mathrm{~min}$, a dose-response curve to angiotensin II was obtained by bolus injections at 5-10 min intervals of $0.05,0.1$, 0.5 and $1.0 \mu \mathrm{g}$ angiotensin II in $0.1 \mathrm{ml}$ saline into the pulmonary arterial line. Angiotensin II was injected at a rate of $0.1 \mathrm{ml} / 10 \mathrm{sec}$. This was followed by injection of $3.5 \mathrm{mg}$ of $\mathrm{KCl}$ in $0.1 \mathrm{ml}$ saline.

Experiment 4: Construction of lung pressure-volume curve. Four weeks after instillation of bleomycin (group B, $n=5,270-280 \mathrm{~g}$ at the time of sacrifice) or saline (group S, $n=$ $4,300-320 \mathrm{~g}$ ), an excised lung pressure-volume curve was constructed. Intraperitoneal pentobarbital anesthesia was followed by tracheostomy, tracheal intubation and $10 \mathrm{~min}$ ventilation with $100 \%$ oxygen. Five min obstruction of the airway made the lung atelectatic through oxygen absorption (Robertson and Farhi 1965). The spinal cord was severed at the thoraco-lumbar junction level. Degassed lungs were inflated by a series of 5 sec infusions, each of $0.59 \mathrm{ml}$, delivered by a glass syringe mounted in a variable-speed infusion-withdrawal pump, each followed by a 5 sec stress relaxation. When the transpulmonary pressure had reached $30 \mathrm{cmH}_{2} \mathrm{O}$, the lungs were deflated by a series of $5 \mathrm{sec}$ withdrawals of $0.59 \mathrm{ml}$, each followed by a 5 sec stress recovery. Three inflation-deflation cycles were obtained and the last deflation limb was analyzed. Zero lung volume was set at the volume of the degassed lungs. Lung volumes were corrected for gas compression.

Data are presented as means \pm s.E. Analysis of variance (ANOVA) was used to test for 
significance of differences between groups and the Student's paired $t$-test for intraindividual differences. Differences were considered significant at $p<0.05$.

\section{Results}

Rats treated with bleomycin did not gain weight during the 4 weeks following instillation. However, the body weight gain of the animals treated with saline was significant during this period $(p<0.01)$ (Table 1 ).

Experiment 1. Elevation of Ppa during the third hypoxic challenge is shown in Fig. 1. Ppa just before the third hypoxia was $19.7 \pm 0.8 \mathrm{cmH}_{2} \mathrm{O}$ for group $\mathrm{S}$ and $23.3 \pm 1.6 \mathrm{cmH}_{2} \mathrm{O}$ for group $\mathrm{B}$. The pressor response of both groups attained plateau levels approximately 4 min after hypoxia and tended to decline afterwards. The magnitude of HPVC did not differ between the two groups. Then we administered ACh 4 min after exposure to hypoxic gas in experiment 2.

Experiment 2. The temporal pattern for HPVC was established on the third or fourth hypoxic challenge. In Fig. 2, Ppa and airway pressure during ACh infusion are shown. This result was obtained from an animal of group $\mathrm{S}$ when ACh was injected into the pulmonary artery in bolus during ongoing HPVC. Airway pressure is depicted only by two lines presenting end-expiratory and inspiratory pressures. ACh depressed Ppa which had been elevated. However, that effect did not last long. In airway pressure, the effect of ACh was observed as a short-term elevation of peak-inspiratory pressure. We took a decrease in Ppa $(\Delta \mathrm{Ppa})$ caused by $\mathrm{ACh}$ as a dilator response to $\mathrm{ACh} . \Delta \mathrm{Ppa}$ was significantly

TABLE 1. Animals' body weight, circulatory and ventilatory conditions

\begin{tabular}{|c|c|c|c|c|c|c|}
\hline & & \multicolumn{2}{|c|}{$\begin{array}{l}\text { Body weight } \\
\text { (g) }\end{array}$} & \multirow[t]{2}{*}{$\begin{array}{c}\mathrm{Ppa} \\
\left(\mathrm{cmH}_{2} \mathrm{O}\right)\end{array}$} & \multirow[t]{2}{*}{$\begin{array}{c}\mathrm{Q} \\
(\mathrm{ml} / \mathrm{min} / \\
100 \mathrm{~g})\end{array}$} & \multirow[t]{2}{*}{$\begin{array}{l}\mathrm{Vt} \\
(\mathrm{ml})\end{array}$} \\
\hline & & Start & End & & & \\
\hline \multirow[t]{2}{*}{ Expt. 1} & Group S (6) & $233 \pm 25$ & $306 \pm 17 \ddagger$ & $15.6 \pm 0.4$ & $4.0 \pm 0.2$ & $3.2 \pm 0.2$ \\
\hline & Group B (6) & $263 \pm 5$ & $278 \pm 15$ & $17.6 \pm 1.2$ & $3.6 \pm 0.1$ & $1.6 \pm 0.1^{* *}$ \\
\hline \multirow[t]{2}{*}{ Expt. 2} & Group $\mathrm{S} \quad$ (7) & $239 \pm 6$ & $296 \pm 8 \ddagger$ & $15.0 \pm 0.1$ & $3.9 \pm 0.1$ & $3.0 \pm 0.0$ \\
\hline & Group B (7) & $266 \pm 4^{* *}$ & $264 \pm 5^{* *}$ & $15.2 \pm 0.2$ & $3.2 \pm 0.1^{* *}$ & $1.6 \pm 0.0^{* *}$ \\
\hline \multirow[t]{2}{*}{ Expt. 3} & Group S (4) & $202 \pm 5$ & $290 \pm 17 \ddagger$ & $14.1 \pm 0.9$ & & $2.9 \pm 0.1$ \\
\hline & Group B (5) & $260 \pm 8^{* *}$ & $277 \pm 2$ & $16.9 \pm 1.0$ & & $1.6 \pm 0.1^{* *}$ \\
\hline \multirow[t]{2}{*}{ Expt. 4} & Group S (4) & $197 \pm 3$ & $307 \pm 5 \ddagger$ & & & \\
\hline & Group B (5) & $260 \pm 8$ & $277 \pm 2$ & & & \\
\hline
\end{tabular}

Means and s.e. are tabulated. Group S, saline-treated group; Group B, bleomycin-treated group; Start, body weight at the injection of bleomycin or saline; End, body weight at the time of sacrifice; Ppa, mean pulmonary artery pressure at the start of the first hypoxic challenge; Q, pulmonary artery flow corrected for body weight; $\mathrm{Vt}$, tidal volume. ${ }^{* *} p<0.01$ as compared with saline group (ANOVA). $\ddagger p<0.01$ as compared with the weight at the instillation (Student's paired $t$-test). Numbers in parentheses represent $(n)$. 


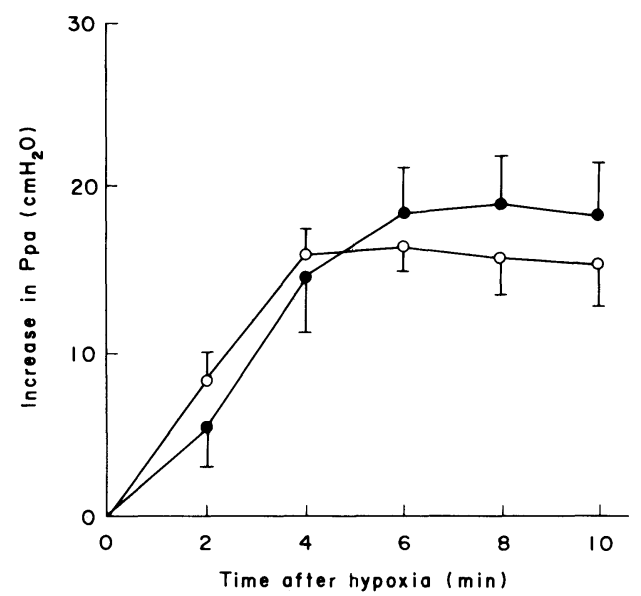

Fig. 1. Ten min hypoxic vasoconstriction. Ppa elevation obtained from the third hypoxic challenge are shown (means and s.e.). Open circles, group $\mathrm{S}$ $(n=6)$; closed circles, group $\mathrm{B}(n=6)$. Ordinate is the absolute change in Ppa. In our experimental system 4 to $6 \mathrm{~min}$ after the start of hypoxia the hypoxic response reached a plateau and then tended to decline in both groups. Both groups responded similarly to hypoxia.

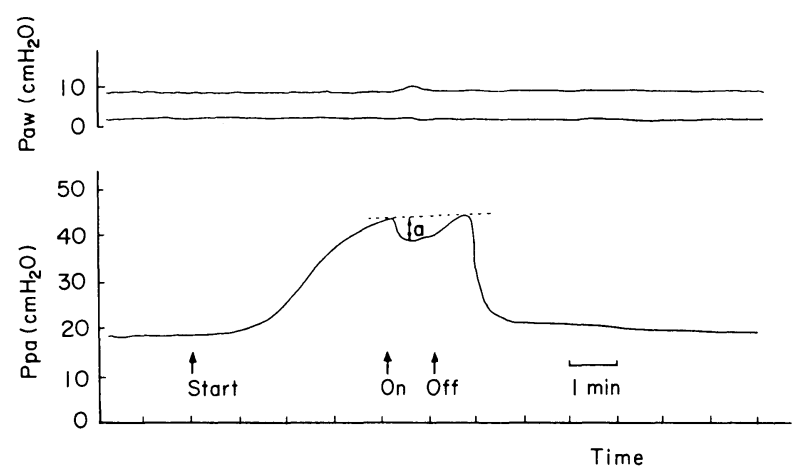

Fig. 2. Airway pressure (Paw) and mean Ppa during ACh infusion. At "start", ventilatory gas was switched from normoxic to hypoxic gas. At "on" and "off", the pump for ACh infusion was started and stopped, respectively. The double-arrow line ( $\downarrow$ a) represents the magnitude of the response to ACh. Only end-inspiratory and end-expiratory airway pressures are shown.

smaller in group $\mathrm{B}$ than in group $\mathrm{S}(p<0.05)$ (Fig. 3). Ppa when ACh was injected did not differ between groups.

Experiment 3. Fig. 4 shows vascular contractions to angiotensin II and $\mathrm{KCl}$. Both groups responded dose-dependently to angiotensin II. There was no significant between-groups difference in response to these vasoconstrictors.

Experiment 4. Mean lung pressure-volume curves are constructed in Fig. 5. Lung volumes corrected for the nose to anus length are shown in order to offset the 


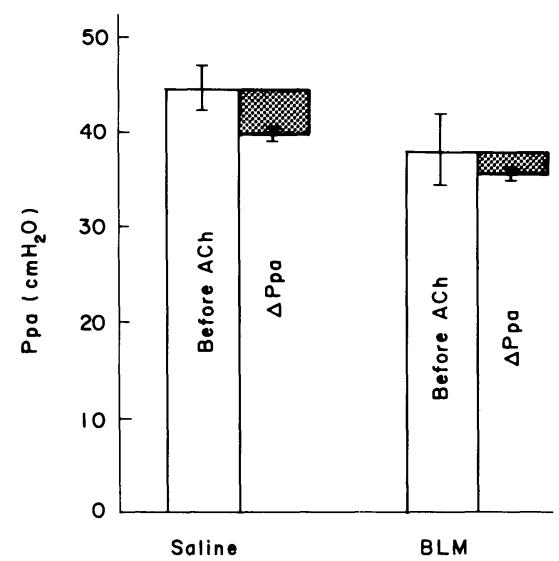

Fig. 3. Pressor responses to $2.5 \mu \mathrm{g}$ of $\mathrm{ACh}$ ( $n=7$ for both groups). Saline, saline-treated group; BLM, bleomycin-treated group. ACh injected during ongoing hypoxic vasoconstriction caused immediate decline of Ppa in both groups as shown in Fig. 2. The columns designated as "before ACh" refer to Ppa when the ACh injection pump was started. Magnitude of decrease in $\mathrm{Ppa}$ in response to $\mathrm{ACh}$ is shown as $\triangle \mathrm{Ppa}$ (shaded columns). The size of decrease in Ppa due to $\mathrm{ACh}$ injection was significantly smaller in group $\mathrm{B}$ than in group $\mathrm{S}(p<0.05)$.

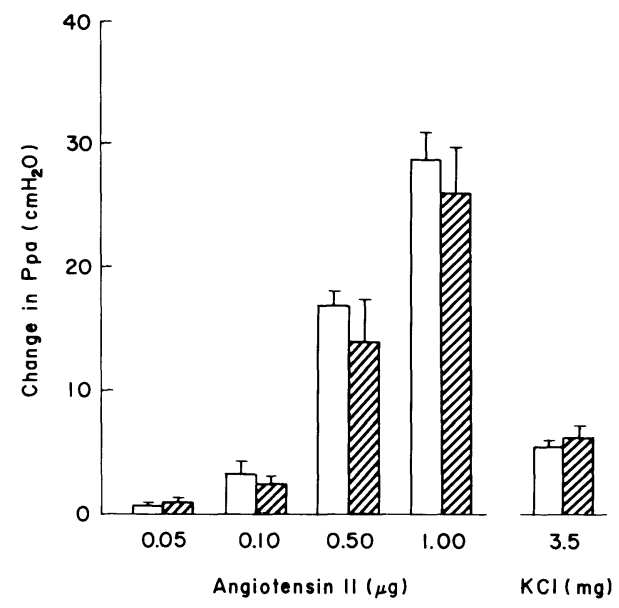

Fig. 4. Vascular contraction to angiotensin II and $\mathrm{KCl} . \quad n=4$ in group $\mathrm{S}$ (open columns), $n=5$ in group B (shaded columns). After the initial equilibration period of $20 \mathrm{~min}$, angiotensin II was infused in bolus in the sequence of 0.05 , $0.10,0.50$ and $1.00 \mu \mathrm{g}$, which was followed by infusion of $3.5 \mathrm{mg}$ of $\mathrm{KCl}$. Twenty min was allowed to pass between the last angiotensin II infusion and $\mathrm{KCl}$ infusion. The responses to these two exogenous vasoactive substances were similar in both groups. 


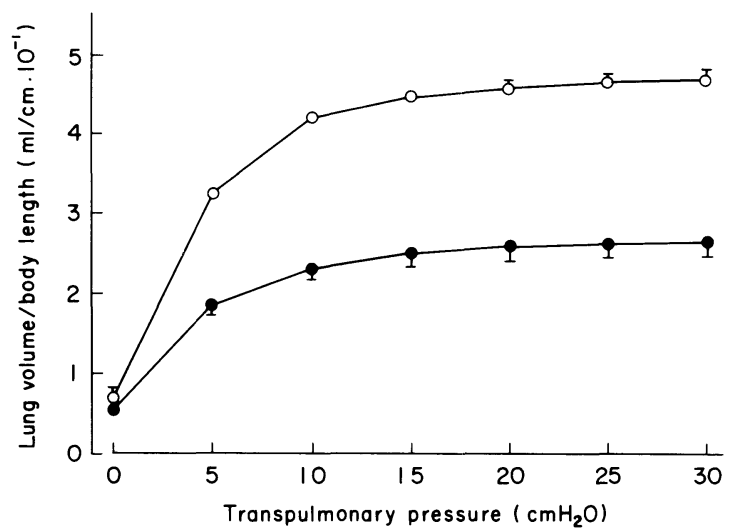

Fig. 5. Lung pressure-volume curves. Open circles, group $\mathrm{S}(n=4)$; closed circles, group $\mathrm{B}(n=5)$. Lung volumes corrected for the nose to anus length are shown in order to cancel differences in animal sizes. Means and s.e. are designated. At any transpulmonary pressure except for zero $\mathrm{cmH}_{2} \mathrm{O}$, lung volumes of group B were significantly smaller than those of group $\mathrm{S}(p<0.01)$.

size-differences in the animals. The curve of group B was remarkably shifted to the right and downward. Mean body length and s.E. was $225 \pm 1 \mathrm{~mm}$ for group $\mathrm{S}$ and $221 \pm 1 \mathrm{~mm}$ for group B. At all transpulmonary pressures, except for zero $\mathrm{cmH}_{2} \mathrm{O}$, and either with or without size correction, lung volumes of the bleomycin

TABLE 2. Effluent blood gas data

\begin{tabular}{|c|c|c|c|c|c|c|}
\hline & \multicolumn{3}{|c|}{ Experiment 1} & \multicolumn{3}{|c|}{ Experiment 2} \\
\hline & $\mathrm{pH}$ & $\begin{array}{l}\mathrm{PCO}_{2} \\
\text { (Torr) }\end{array}$ & $\begin{array}{c}\mathrm{PO}_{2} \\
\text { (Torr) }\end{array}$ & $\mathrm{pH}$ & $\begin{array}{l}\mathrm{PCO}_{2} \\
\text { (Torr) }\end{array}$ & $\begin{array}{c}\mathrm{PO}_{2} \\
\text { (Torr) }\end{array}$ \\
\hline \multicolumn{7}{|l|}{ Group S } \\
\hline Start $\mathrm{M}_{ \pm \text {s.E. }}$ & $\begin{array}{r}7.377 \\
\pm 0.006\end{array}$ & $\begin{array}{r}35.5 \\
\pm 0.5\end{array}$ & $\begin{array}{l}150.0 \\
\pm 2.7\end{array}$ & $\begin{array}{c}7.384 \\
\pm 0.006 \ddagger\end{array}$ & $\begin{array}{c}35.3 \\
\pm 0.5 \ddagger\end{array}$ & $\begin{array}{l}144.5 \\
\pm 1.9 \ddagger\end{array}$ \\
\hline End $\mathrm{M} \pm$ S.E. & $\begin{array}{r}7.416 \\
\pm 0.006\end{array}$ & $\begin{array}{r}33.7 \\
\pm 1.5\end{array}$ & $\begin{array}{r}26.7 \\
\pm 1.7\end{array}$ & $\begin{array}{r}7.414 \\
+0.010\end{array}$ & $\begin{array}{r}33.4 \\
\pm 0.5\end{array}$ & $\begin{array}{c}31.0 \\
\pm 0.9 \ddagger\end{array}$ \\
\hline \multicolumn{7}{|l|}{ Group B } \\
\hline Start $\mathrm{M} \pm$ s.E. & $\begin{array}{r}7.394 \\
\pm 0.011\end{array}$ & $\begin{array}{c}31.6 \\
\pm 1.4^{*}\end{array}$ & $\begin{array}{l}139.4 \\
\pm 4.2^{*}\end{array}$ & $\begin{array}{r}7.382 \\
\pm 0.004\end{array}$ & $\begin{array}{l}31.4 \\
\pm 0.7^{* *} \ddagger\end{array}$ & $\begin{array}{r}139.5 \\
\pm 4.2\end{array}$ \\
\hline End $\mathrm{M} \pm$ s.E. & $\begin{array}{r}7.427 \\
\pm 0.010\end{array}$ & $\begin{array}{r}30.6 \\
\pm 1.2\end{array}$ & $\begin{array}{r}27.9 \\
\pm 1.1\end{array}$ & $\begin{array}{r}7.421 \\
\pm 0.004\end{array}$ & $\begin{array}{l}28.8 \\
\pm 0.5^{* * \ddagger}\end{array}$ & $\begin{array}{l}39.8 \\
\pm 1.6^{* *} \ddagger\end{array}$ \\
\hline
\end{tabular}

Means and S.E. are tabulated. Presented are the data obtained from the hypoxic challenge in experiment 2 in which $\mathrm{ACh}$ was infused, and the data obtained from the third hypoxic challenge in experiment 1. Group S, saline-treated group; Group B, bleomycin-treated group; $\mathrm{PCO}_{2}$ and $\mathrm{PO}_{2}$, carbon dioxide and oxygen tension, respectively. Start and End refer to the time at the start and the end of the hypoxic challenge, respectively. $n=7$ in experiment 2 , and $n=6$ in experiment 1 if not noted as $\ddagger$ (when there is $\ddagger, n=5$ for technical error), ${ }^{*} p<0.05{ }^{* *} p<0.01$ when compared with group $\mathrm{S}$. 
group were significantly smaller than those of the saline group $(p<0.01)$. Total lung capacity of group B, defined as air volume at $30 \mathrm{cmH}_{2} \mathrm{O}$ of transpulmonary pressure, was approximately half that of group $\mathrm{S}$.

Blood gas data. Effluent blood gas data are shown in Table 2. $\mathrm{pH}$ values were similar in both groups in experiment 1 and 2 . Whereas $\mathrm{PCO}_{2}$ and $\mathrm{PO}_{2}$ of group $\mathrm{B}$ were usually slightly but significantly lower than those of group $\mathrm{S}$ at the starting time. In experiment $2, \mathrm{PCO}_{2}$ of group $\mathrm{B}$ was significantly lower than that of group $\mathrm{S}(p<0.01)$ and $\mathrm{PO}_{2}$ of group $\mathrm{B}$ was higher than that of group $\mathrm{S}$ at the end of hypoxia $(p<0.01)$.

\section{Discussion}

The purpose of the present study was to assess the functional integrity of endothelial cells with dilator response of pulmonary vasculature to $\mathrm{ACh}$ as an indicator in a disease model of idiopathic pulmonary fibrosis. The results demonstrated that dilator response to $\mathrm{ACh}$ tested during ongoing $\mathrm{HPVC}$ was significantly diminished, whereas the pressor responses to angiotensin $\mathrm{II}$ and $\mathrm{KCl}$ were not affected. The lungs of bleomycin-treated groups were remarkably stiff as judged from lung pressure-volume curve.

Before focusing on the results described above, we would like to discuss briefly the experimental system. HPVC is influenced not only by alveolar gas $\mathrm{PO}_{2}$ but also by perfusate $\mathrm{PO}_{2}$ (Hyman et al. 1981; Marshall and Marshall 1983), although alveolar $\mathrm{PO}_{2}$ is much more predominant. With our experimental system, $\mathrm{PO}_{2}$ of the effluent blood in group $\mathrm{B}$ was lower at the start in experiment 1 and higher at the end of the hypoxic period in experiment 2 than those in group $\mathrm{S}$ (Table 2). This was probably due to a decrease in the number of gasexchangeable alveoli, relatively lower perfusate flow rate and/or shunt flow in group B. As the perfusate from the pulmonary venous line was recirculated in a semi-closed system, influent blood should have gas components similar to those of effluent blood. Such $\mathrm{PO}_{2}$ locus, i.e., lower at the start and higher at the end of the hypoxic period, should have caused delay of HPVC in group B. However, we have never read papers showing that the dilator response to $\mathrm{ACh}$ is influenced by the late manifestation of HPVC. $\mathrm{PCO}_{2}$ of the effluent blood was also lower in group B. However, Malik and Kidd (1973) reported that when the hydrogen ion concentration of the blood was controlled at resting levels, decrease in blood $\mathrm{PCO}_{2}$ had no effect on pulmonary vascular response to hypoxia. According to their data, if $\mathrm{pH}$ is maintained constant, reduction in arterial $\mathrm{PCO}_{2}$ from 40 Torr to 15 Torr did not alter the pulmonary vascular response to hypoxia. In both experiment 1 and 2, hydrogen ion concentration did not differ between the groups (Table $2)$.

Since the response to $\mathrm{ACh}$ of a preconstricted blood vessel is endotheliumdependent (Furchgott and Zawadzki 1980), the hypo-responsiveness to ACh in group B probably reflects an impairment of endothelial cell function. Response 
to ACh is also dependent on vascular tone (Hyman and Kadowitz 1988, 1989) as a many other vasodilators. Mean Ppa when $\mathrm{ACh}$ was infused was $44.4 \mathrm{cmH}_{2} \mathrm{O}$ in group $\mathrm{S}$ and $37.9 \mathrm{cmH}_{2} \mathrm{O}$ in group $\mathrm{B}$. Did the $6.5 \mathrm{cmH}_{2} \mathrm{O}$ difference of preinfusion pulmonary artery tone in our experimental pressure range cause the apparently weaker responsiveness in group B ? There have been no reports directly adrressing this question. We plotted the relationship between the magnitude of dilator response to ACh versus pre-infusion Ppa. No significant relation was found $(\mathrm{r}=$ 0.19 for linear regression $n=14$ ). Therefore, we speculate that our results are not attributable to the difference of pre-infusion pulmonary artery tone but to the other cause, probably to the dysfunction of pulmonary endothelial cells in the bleomycin-treated group. Experiment reported by Catravas et al. (1983) support our speculation. This experiment demonstrated that intratracheal administration of bleomycin to rabbit could produce endothelial dysfunction.

Antagonists of EDRF augment HPVC in isolated perfused rat rung which is the same experimental system used in our study (Brashers et al. 1988). The authors suggested an important role for endothelium in pulmonary vascular response to alveolar hypoxia. Why did not the poor response to $\mathrm{ACh}$, possibly due to the diminished release of EDRF, cause augmented HPVC in the present study? There may have been a decrease in vasoconstrictor signal which comes from lung endothelium. Lung endothelium performs a variety of biochemical functions, such as hydrolysis of angiotensin I to angiotensin II (Fanburg and Glazier 1973; Szidon et al. 1983) and uptake and metabolism of prostaglandins (Robinson et al. 1985). However, another explanation is also possible. Presently it is accepted that total pulmonary vascular resistance is determined by two portions of the pulmonary vascular bed, namely the alveolar and extra-alveolar segments, which are affected oppositely by increases in transpulmonary pressure (Howel et al. 1961 ; Lopez-Munitz et al. 1968). The alveolar vessels are stretched and narrowed as the lung is expanded, resulting in an elevation of vascular resistance. However, in the present study lung inflation pressure remained the same, therefore alveolar pressure was the same in both groups. The extra-alveolar vessels within the lung parenchyma, on the other hand, are distended because of their interdependence with the surrounding lung. Pathological studies on lungs treated with intratracheal bleomycin showed perivascular fibrosis and thickening of alveolar septa. These histological changes are wide spread but irregular in distribution, and the alveoli in these areas are atelectatic or diminished in volume (Snider et al. 1978a). This makes distribution of elastic recoil pressure uneven. To the extra-alveolar vessels within the atelectatic regions or regions where volume is less, stronger outward traction against the inward force produced by hypoxic vasoconstriction is applied than to the vessels within the normal parenchyma even with the same inflation pressure in a lung (Mead et al. 1970; Quebbeman and Dawson 1976, 1977). This mechanism can cancel the elevated inward force due to augmented hypoxic pulmonary vasoconstriction in the 
presence of decreased secretion of endothelium-derived relaxing factor in group B.

In summary, our results indicate that vasodilator response to $\mathrm{ACh}$ was attenuated in bleomycin-treated isolated rat lungs. This was possibly caused by the impaired release of EDRF from the lung endothelium damaged by bleomycin.

\section{References}

1) Boeynaems, J.M. \& Galand, N. (1983) Cholinergic stimulation of vascular prostacyclin synthesis. Prostaglandins, 26, 531-544.

2) Brashers, V.L., Peach, M.J. \& Rose, C.E., Jr. (1988) Augmentation of hypoxic vasoconstriction in the isolated perfused rat lung by in vitro antagonists of endothelium-dependent relaxation. J. Clin. Invest., 82, 1495-1502.

3) Catravas, J.D., Lazo, J.S., Dobuler, K.J., Mills, L.R. \& Gillis, C.N. (1983) Pulmonary endothelial dysfunction in the presence or absence of interstitial injury induced by intra-tracheally injected bleomycin in rabbits. Am. Rev. Respir. Dis., 128, 740746.

4) De Mey, J.G. \& Vanhoutte, P.M. (1982) Heterogeneous behavior of the canine arterial and venous wall. Importance of the endothelium. Circ. Res., 51, 439-447.

5) Fanburg, B.L. \& Glazier, J.B. (1973) Conversion of angiotensin I to angiotensin II in the isolated perfused dog lung. J. Appl. Physiol., 35, 325-331.

6) Fasske, E. \& Morgenroth, K. (1983) Experimental bleomycin lung in mice. Lung, 161, 133-146.

7) Feddersen, C.O., Mathias, M.M., McMurtry, I.F. \& Voelkel, N.F. (1986) Acetylcholine induces vasodilation and prostacyclin synthesis in rat lungs. Prostaglandins, 31, 973-987.

8) Furchgott, R.F. \& Zawadzki, J.V. (1980) The obligatory role of endothelial cells in the relaxation of arterial smooth muscle by ACh. Nature, 288, 373-376.

9) Hauge, A. (1968) Conditions governing the pressor response to ventilation hypoxia in isolated perfused rat lungs. Acta Physiol. Scand., 72, 33-44.

10) Holden, W.E. \& McCall, E. (1984) Hypoxia-induced contractions of porcine pulmonary artery strips depend on intact endothelium. Exp. Lung Res., 7, 101-112.

11) Howel, J.B.L., Permutt, S., Proctor, D.F. \& Riley, R.L. (1961) Effect of inflation of the lung on different parts of pulmonary vascular bed. J. Appl. Physiol., 16, 71-76.

12) Hyman, A.L. \& Kadowitz, P.J. (1988) Tone-dependent responses to Acetylcholine in the feline pulmonary vascular bed. J. Appl. Physiol., 64, 2002-2009.

13) Hyman, A.L. \& Kadowitz, P.J. (1989) Influence of tone on responses to acetylcholine in the rabbit pulmonary vascular bed. J. Appl. Physiol., 67, 1388-1394.

14) Hyman, A.L., Higashida, R.T., Spannhake, E.W. \& Kadowitz, P.J. (1981) Pulmonary vasoconstrictor responses to graded decreases in precapillary blood $\mathrm{PO}_{2}$ in intact-chest cat. J. Appl. Physiol.: Respirat. Environ. Exercise Physiol., 51, 10091016.

15) Lopez-Munitz, R., Stephens, N.L., Bromberger-Barnea, B., Permutt, S. \& Riley, R.L. (1968) Critical closure of pulmonary vessels analyzed in terms of Starling resistor model. J. Appl. Physiol., 24, 625-635.

16) Malik, A.B. \& Kidd, B.S.L. (1973) Independent effects of changes in $\mathrm{H}^{+}$and $\mathrm{CO}_{2}$ concentrations on hypoxic pulmonary vasoconstriction. J. Appl. Physiol., 34, 318323.

17) Marshall, C. \& Marshall, B.E. (1983) Influence of perfusate $\mathrm{PO}_{2}$ on hypoxic pulmonary vasoconstriction in rats. Circ. Res., 52, 691-696.

18) McMurtry, I.F., Davidson, A.B., Reeves, J.T. \& Grove, R.F. (1976) Inhibition of hypoxic pulmonary vasoconstriction by calcium antagonists in isolated rat lungs. Circ. Res., 38, 99-104. 
19) Mead, J., Takishima, T. \& Leith, D.E. (1970) Stress distribution in lungs : A model of pulmonary elasticity. J. Appl. Physiol., 28, 596-608.

20) Quebbeman, E.J. \& Dawson, C.A. (1976) Influence of inflation and atelectasis on the hypoxic pressor response in isolated dog lung lobes. Cardiovasc. Res., 10, 672-677.

21) Quebbeman, E.J. \& Dawson, C.A. (1977) Effect of lung inflation and hypoxia on pulmonary arterial blood volume. J. Appl. Physiol.: Respirat. Environ. Exercise Physiol., 43, 8-13.

22) Robertson, W.G. \& Farhi, L.E. (1965) Rate of lung collapse after airway occlusion on $100 \% \mathrm{O}_{2}$ at various ambient pressures. J. Appl. Physiol., 20, 228-232.

23) Robinson, C., Hardy, C.C. \& Holgate, S.T. (1985) Pulmonary synthesis, release, and metabolism of prostaglandins. J.Allergy Clin. Immunol., 76, 265-271.

24) Snider, G.L., Celli, B.R., Goldstein, R.H., O’Brien, J.J. \& Lucey, E.C. (1978a) Chronic interstitial pulmonary fibrosis produced in hamsters by endotracheal bleomycin. Lung volumes, volume-pressure relations, carbon monoxide uptake, and arterial blood gas studies. Am. Rev. Respir. Dis., 117, 289-297.

25) Snider, G.L., Hayes, J.A. \& Korthy, A.L. (1978b) Chronic interstitial pulmonary fibrosis produced in hamsters by endotracheal bleomycin. Pathology and stereology. Am. Rev. Respir. Dis., 117, 1099-1108.

26) Szidon, P., Oparil, S., Booyse, F.M. \& Osikowicz, G. (1983) Effect of hypoxia on the angiotensin metabolism by cultured endothelial cells. Biochem. Pharmacol., 32, 1201-1205. 